\title{
Improved silver technique for showing nucleolar organiser regions in paraffin wax sections
}

\author{
K Y CHIU, S L LOKE, K K WONG Histopathology Unit, Department of Pathology, University of \\ Hong Kong, Queen Mary Hospital, Hong Kong
}

SUMMARY An improved technique for the demonstration of nucleolar organiser regions (NORs) was devised. It has the advantage that any non-specific background deposits which mimic the NOR dots formed during staining are trapped by the celloidin film. The specificity of the silver staining is also increased by the postfixation treatment of sections in an acetic acid-ethanol mixture. Moreover, it is economical because of the low silver content and small volume of the incubation solution used.

Nucleolar organiser regions (AgNORs) that show an argyophilic reaction are loops of ribosomal DNA which are present in the nucleoli of cells and which transcribe to ribosomal RNA. AgNORs are important during the ultimate synthesis of protein. ${ }^{12}$ AgNORs have been shown by staining using a onestep silver colloid method at $70^{\circ} \mathrm{C}$ to identify certain trisomies in chromosomal metaphase spreads. ${ }^{3} \mathrm{~A}$ modified version of Ploton et al $\mathrm{s}$ method means that this technique can be applied to paraffin wax sections at $20^{\circ} \mathrm{C}$ to minimise the troublesome background deposits. ${ }^{4}$ In our experience, however, we found some fine silver precipitates on the specimen which may be mistaken for AgNOR dots, especially when they are located in the nuclei; these may produce a false positive result. The aim of this study was to develop an improved technique.

\section{Material and methods}

Sections $(2 \mu \mathrm{m})$ of routinely formalin fixed, paraffin wax embedded blocks were cut, dewaxed in xylene, and transferred to absolute ethanol. The sections were treated with an acetic acid-ethanol (1:3) mixture for five minutes and rinsed with absolute ethanol. They were then transferred to $1 \%$ celloidin in equal parts of ethanol and ether for one minute. The excess celloidin was drained off and the slides were transferred to $70 \%$ ethanol to harden the celloidin. The slides were washed in distilled water ready for AgNOR staining.

The silver colloid solution for staining AgNOR was prepared by dissolving $2 \mathrm{~g} / \mathrm{dl}$ gelatin in $1 \mathrm{~g} / \mathrm{dl}$ aqueous formic acid. This was mixed in a ratio of 1:2 volumes with a $20 \mathrm{~g} / \mathrm{dl}$ aqueous silver nitrate solution. The

Accepted for publication 31 March 1989 working solution was dropped on to the sections and incubated for 30 minutes at $45^{\circ} \mathrm{C}$. After this, the sections were washed thoroughly with hot $\left(45^{\circ} \mathrm{C}\right)$ distilled water, dehydrated, cleared and mounted in Permount.

\section{Results}

The AgNORs appeared within the nuclei as darke brownish dots of varying sizes against a yellowbackground. They were widely distributed in the nuclei, and smaller AgNORs, which were not easily recognised as nucleoli with haematoxylin and eosin staining, were also shown (fig la).

\section{Discussion}

The AgNOR technique has recently been applied in histopathology for investigating malignant tissues in man. It has been found that the number of AgNORs in nuclei may reflect the state of activation or grade of malignancy. ${ }^{4}$ Crocker and Nar applied this technique to non-Hodgkin's lymphomas and showed that the number of AgNOR dots within the nuclei was much greater in high grade than in low grade non-Hodgkin's lymphomas. ${ }^{5}$ Similarly, Crocker et al, ${ }^{6}$ Egan et al, ${ }^{7}$ and Smith $e \mathrm{al}^{8}$ also applied it to the study of melanocytic lesions of skin, cutaneous tumours, and breast tumours, respectively. Their results indicated that both benign and malignant tumours had different mean numbers of AgNORs. A disadvantage of the AgNOR technique, however, is the formation of silver precipitates during staining which may be mistaken for AgNOR dots, especially when they are located within the nuclei. This will exaggerate the NOR counts for each nucleus and produce an inaccurate statistical result. The formation of the silver deposits increases as 


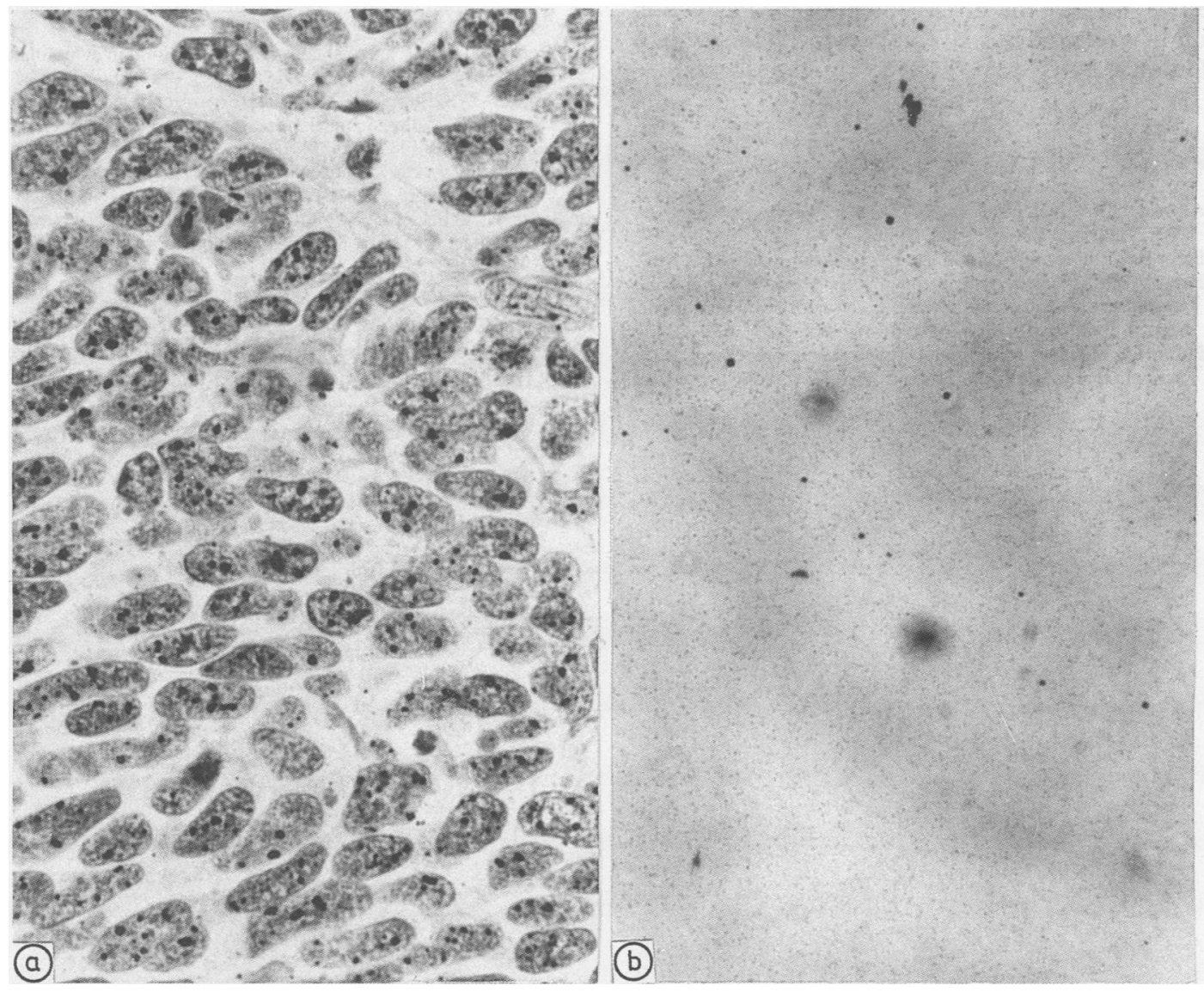

Figure 1 Photomicrograph of a poorly differentiated squamous cell carcinoma of the oesophagus (a) stained with improved silver colloid technique for AgNORs. Numerous AgNORs of varying sizes are easily recognised as discrete dark brownish dots within the nuclei of the cell. (b) Same visual field as in (a) but focused at a different level to show the presence of silver precipitates trapped on the celloidin film. Some of the precipitates are similar in colour and size to AgNORs. Finer precipitates are also trapped, resulting in a much cleaner background.

the staining time is prolonged. Therefore, the optimal staining time should be kept to between $30-45$ minutes to minimise heavy non-specific background staining.

We improved the one-step silver staining by: (i) postfixation of sections in acetic acid-ethanol during rehydration; (ii) covering the sections before staining with celloidin; and (iii) reducing the concentration of the silver nitrate solution from $50 \%$ to $20 \%$.

The action of the acetic acid-ethanol mixture in our technique is uncertain. We presumed that the mixture is used to increase the permeability of cells, thus facilitating the penetration of staining solution. Celloidin hardening has been used to prevent the detachment of sections from slides during staining with a highly alkaline solution. We also noted that this procedure can sometimes be applied to prevent dye precipitation on to sections in a volatile staining solution such as Best's carmine. Similarly, in our study it acted as a barrier to block any silver precipitates or non-specific background deposits, formed during staining, from adhering to the sections. As a result, the silver precipitates were trapped on the celloidin film (fig lb). Because the section and the celloidin film are focused at different levels, the Ag-NORs are the only black dots visualised when the section is in focus. Besides, the barrier effect is enhanced when gelatin is present in the staining solution. Gelatin was originally used as a protective colloid to control the silver staining. It is not known why gelatin enhances the barrier effect. Another advantage is that the staining does not have to be performed in a dark room to minimise background deposits. Moreover, it is cost 
effective, because the silver content of the incubation solution is reduced by half compared with the method of Ploton et al. ${ }^{4}$

\section{References}

1 Alberts B, Bray D, Lewis J, et al. Molecular biology of the cell. New York: Garland Publishing, 1983:424-6.

2 Perry RP. Processing of RNA. Ann Rev Biochem 1976;45:605-29.

3 Howell WM, Black DA. Controlled silver-staining of nucleolus organizer regions with a protective colloidal developer: a onestep method. Experientia 1980;36:1104-5.

4 Ploton D, Menager M, Jeannesson P, et al. Improvement in the staining and in the visualization of the argyrophilic proteins of the nucleolar organizer region at the optical level. Histochem $J$ 1986;18:5-14.

5 Crocker J, Nar P. Nucleolar organizer regions in lymphomas. $J$ Pathol 1987;151:111-18.

6 Crocker J, Skilbeck N. Nucleolar organizer region associated proteins in cutaneous melanotic lesions: a quantitative study. $J$ Clin Pathol 1987;40::885-9.

7 Egan MJ, Crocker J. Nucleolar organizer regions in cutaneous tumours. J Pathol 1988;154:247-53.

8 Smith R, Crocker J. Evaluation of nucleolar organizer regionassociated proteins in breast malignancy. Histopathology 1988;12:113-25.

Requests for reprints to: Dr K Y Chiu, Histopathology Unit, Department of Pathology, University of Hong Kong, Queen Mary Hospital Compound, Pokfulam Road, Hong Kong. 